Journal of Theoretical and Applied Mechanics, Sofia, Vol. 47 No. 4 (2017) pp. 12-22

\title{
DEVELOPMENT OF HAND-HELD SURGICAL ROBOT ODRO-2 FOR AUTOMATIC BONE DRILLING
}

\author{
George Boiadjiev ${ }^{1,2 *}$, IVAn Chavdarov ${ }^{3}$, Kamen Delchev ${ }^{2}$, \\ TONY BOIADJIEV ${ }^{4}$, RUMEN KASTELOV ${ }^{5}$, KAZIMIR ZAGURKI ${ }^{3}$ \\ ${ }^{1}$ Faculty of Mathematics and Informatics, Sofia University, 5 J. Boucher Blvd, \\ 1164 Sofia, Bulgaria \\ ${ }^{2}$ Institute of Mechanics, Bulgarian Academy of Sciences,Acad. G. Bonchev \\ St., Bl. 4, 1113 Sofia, Bulgaria \\ ${ }^{3}$ Institute of System Engineering and Robotics, Bulgarian Academy of \\ Sciences, Acad. G. Bonchev St., Bl. 2, 1113 Sofia, Bulgaria \\ ${ }^{4}$ Institute of Information and Communication Technologies, Bulgarian \\ Academy of Sciences, Acad. G. Bonchev St., Bl. 2, 1113 Sofia, Bulgaria \\ ${ }^{5}$ Orthopaedic and Trauma Clinical Centre of Ministry of Interior, 79 Skobelev \\ Blvd, 1606 Sofia, Bulgaria
}

[Received 21 September 2017. Accepted 4 December 2017]

\begin{abstract}
This paper represents the development of a prototype robotic system for automatic bone drilling in orthopaedic surgery. A new design of the mechanical structure is proposed, answering the surgical requirements for the robot dimensions and weight to be as small as possible. The new structure design is based on idea of parallelism of the axis of the linear actuator and the axis of the rotary one. The control system is improved by using a new microcontroller. A new type of linear drive and a new force sensor (load cell) are built in, so that the quality characteristics of the "Orthopaedic bone Drilling Robot" (ODRO) are not only the same as previous its two versions, but becomes better.

An experimental setup is arranged and experiments are executed to test and to verify the robot quality features and functional capabilities.
\end{abstract}

KEY WORDS: Automatic bone drilling, orthopaedic surgery, experiments

\section{INTRODUCTION}

The drilling of bones is one of the most important manipulations in the orthopaedic surgery. Spine column pedicle, hip head arthroplasty, various type of femur fractures are some examples, where such a manipulation take place and orthopaedic screws are implanted in the bones after drilling. This operation is executed relying on the subjective factor or simply saying - the surgeon's skills, i. e. handily. That's a reason for appearance of some problems reflecting to the operation quality, as precision and

\footnotetext{
*Corresponding author e-mail: george@imbm@bas.bg
} 
overheating [1] mainly or even mistakes - the average error in bi-cortical drilling is $6.31 \mathrm{~mm}$ ! [2]. Also, by reports, such a breakthrough may cause additional damage of the soft tissue as tendons, blood vessels etc. [2-4]. The "acceptable" precision by surgeon's opinion is about $1-2 \mathrm{~mm}$, but it is very difficult to realize it constantly for any operation. The help comes from the automatic drilling with robot application. Some well-known robotized systems are developed in US, UK, Israel etc. [5-8].

The drilling process depends on lots of parameters, but the most important one is the thrust force, applied during the drilling execution [9]. It influences both the precision and the temperature. An interesting attempt to reduce the thrust force is the so called ultrasonically-assisted drilling of cortical bone [10].

We developed a robotized system ODRO for automatic bone drilling in the orthopaedic surgery. Its components, mechanical design, drives, controllers, electronics, program environment, language and software are published in [11-20]. Also, there are discussed some specific practical tasks, solved by the robot.

This paper represents the development of a new prototype of robotic system for automatic bone drilling in the orthopaedic surgery. A new design of the mechanical structure is proposed, answering the surgical requirements for the robot dimensions and weight to be as small as possible. The new structure design is based on the idea of axis parallelism of the linear actuator and the axis of the rotary one. The control system is improved by using a new micro-controller. A new type of linear drive and a new force sensor (load cell) are built in, so that the quality characteristics of the "Orthopaedic Bone Drilling Robot" (ODRO) are not only the same as previous its two versions but become better.

An experimental setup is arranged and experiments are executed to test and to verify the robot quality features and functional capabilities.

\section{ROBOTIZED SYSTEM ODRO-2}

The new structural scheme is shown in Fig. 1 and presents the parallel axes of the linear drive and the rotary one, instead of collinear case (the old one can be seen in [15]).

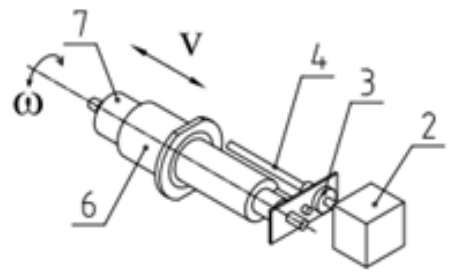

Fig. 1. Structural scheme of ODRO2 with parallel axes between the linear drive (No 4) and the rotary one (No 7). 
14 G. Boiadjiev, I. Chavdarov, K. Delchev, T. Boiadjiev, R. Kastelov, K. Zagurki

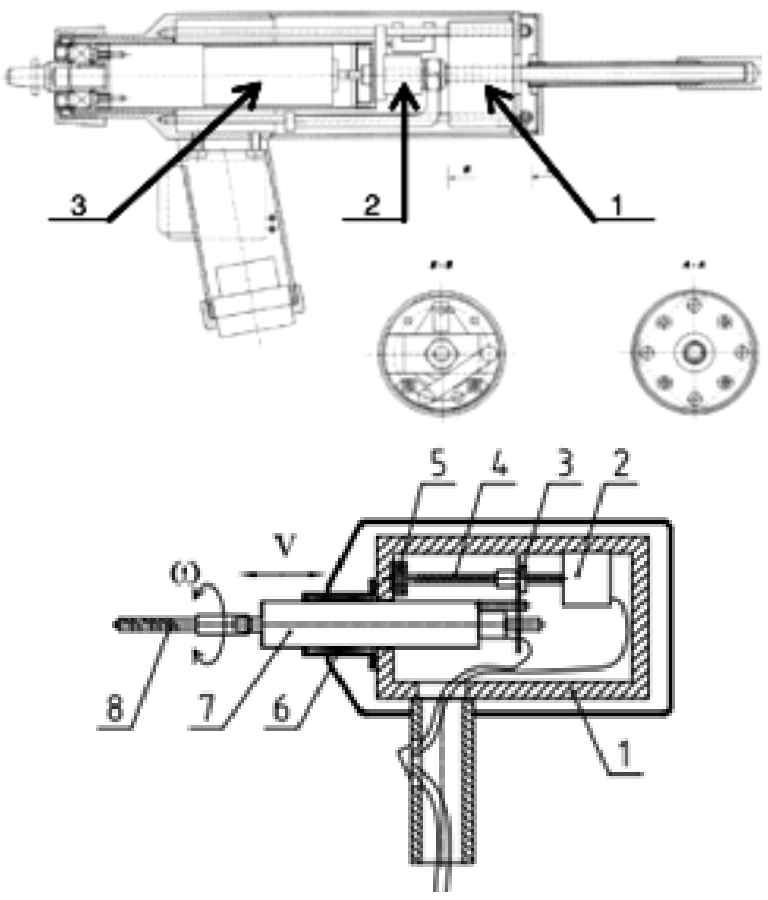

Fig. 2. The old mechanical structure (upper) and the new mechanical structure (lower).

This kinematic scheme allows designing a new mechanical structure (Fig. 2 lower), where the advantage is to shorten the robot by one third in length. For the first one-the numbers 1, 2, 3 indicate the linear drive, the load cell and the rotary drive; for the second one-mechanical structure the corresponding numbers are 2, 4 and 7.

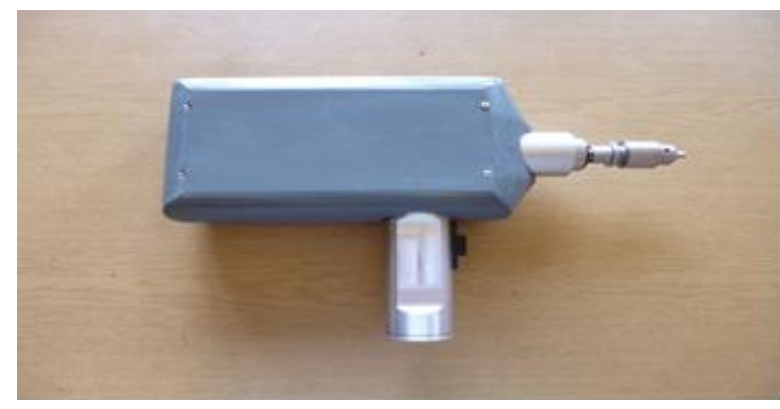

Fig. 3. Automatic drilling executive device. 


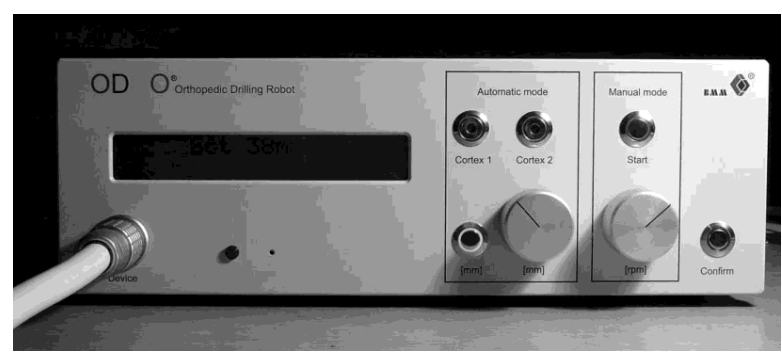

Fig. 4. Control and power block.

In Fig. 3 the new prototype of automatic drilling device of the robot ODRO-2 is shown. The power and the control block are shown in Fig. 4. It is the same one like the previous, but new micro-controller, new force sensor (load cell LMB-A-200N) and new amplifier WGA-100B-10 (Kyowa, Japan) are incorporated in replacing the former ones.

Some characteristics of the load cell LMB-A-200N used here are shown in Tables 1-4, below:

Table 1. Performance

\begin{tabular}{lr|}
\hline \hline Rated capacity: & $200 \mathrm{~N}$ \\
Nonlinearity: & within $\pm 0.5 \% \mathrm{RO}$ \\
Hysteresis: & within $\pm 0.5 \% \mathrm{RO}$ \\
Repeatability: & $0.3 \%$ RO or less \\
Rated output: & $1.4 \mathrm{mV} / \mathrm{V}$ or more \\
\hline
\end{tabular}

Table 2. Environmental characteristics

\begin{tabular}{|} 
Safe temperature: \\
-10 to $80^{\circ} \mathrm{C}$ (non-condensing) \\
Compensated temperature: \\
0 to $70^{\circ} \mathrm{C}$ (non-condensing) \\
Temperature effect on zero: \\
within $\pm 0.05 \% \mathrm{RO} / \mathrm{deg}$ \\
Temperature effect on output: \\
within $\pm 0.05 \% / \mathrm{deg}$
\end{tabular}

Table 3. Electrical Characteristics

\begin{tabular}{|lr|}
\hline Safe excitation: & $7 \mathrm{~V} \mathrm{AC}$ or DC \\
Recommended excitation: & 1 to $5 \mathrm{~V} \mathrm{AC}$ or DC \\
Input resistance: & $350 \Omega \pm 2.5 \%$ \\
Output resistance: & $350 \Omega \pm 2.5 \%$ \\
Cable: & \\
4-conductor $\left(0.035 \mathrm{~mm}^{2}\right)$ vinyl shielded cable, \\
$1.7 \mathrm{~mm}$ diameter by $2 \mathrm{~m}$ long, bared at the tip \\
\hline
\end{tabular}

Table 4. Mechanical properties

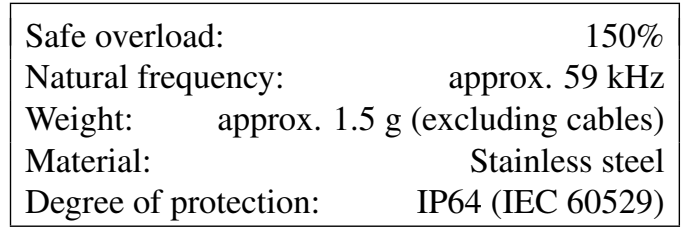

The bone drilling robot maintains two working modes: handily and automatic. It works as usual drilling machine in handily mode. The rotation speed can be regulated by potentiometer.

The automatic mode has two sub-modes: bi-cortical drilling (Cortex I, Cortex II) 
and drilling at the preliminary set depth $(\mathrm{mm})$. The algorithm for preliminary set depth execution (precision is $0.1 \mathrm{~mm}$ ) is discussed in details in [9].

Sub-modes are chosen by the surgeon with the help of four buttons and potentiometer connected with display.

\section{EXPERIMENTAL SETUP}

The software control of the thrust force during the drilling process is possible to be realized only if the surgeon maintains the hard connection with the bone all the time. The way of hard connection between the bone and the executive device corpse is seen in the setup, arranged for experiments with bovine bone (Fig. 5).

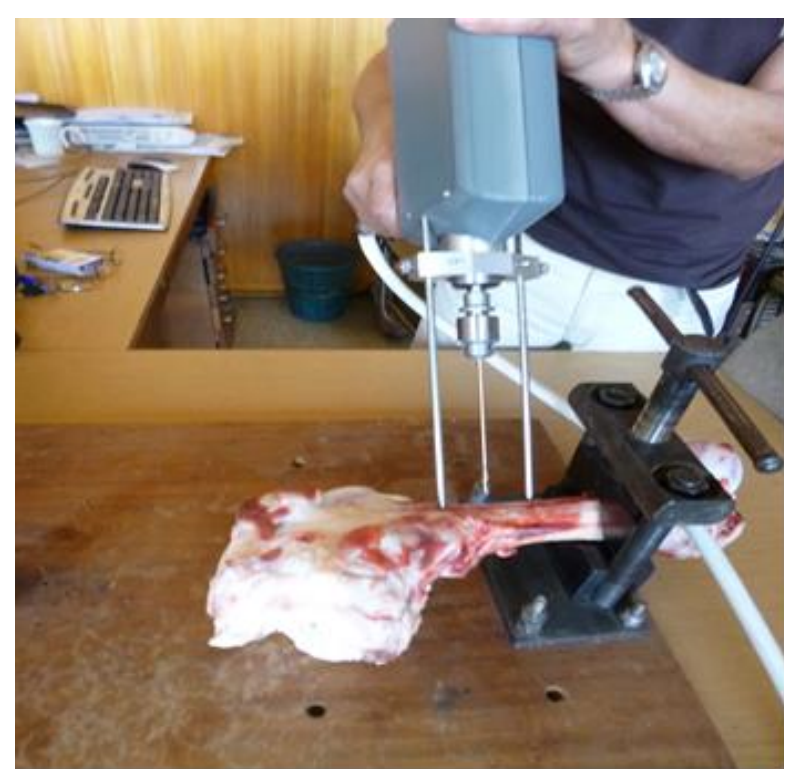

Fig. 5. Experimental setup and bovine bone drilling execution.

\section{EXPERIMENTAL DATA AND MANIPULATION PRECISION}

The manipulation precision concerns the moment of time, when the drilling ends. The end task decision depends on the achievement of the preliminary given depth, or the far cortex end registration. Coming close to the bone wall end, the speed is reduced to prevent the debris appearance and assure minimal penetration after the breakthrough.

Experimental data are presented in Fig. 6 for the thrust force deviation with respect to time during bi-cortical drilling of bovine bone, entirely. It is monitored continuously all the time. 


\section{Thrust Force}

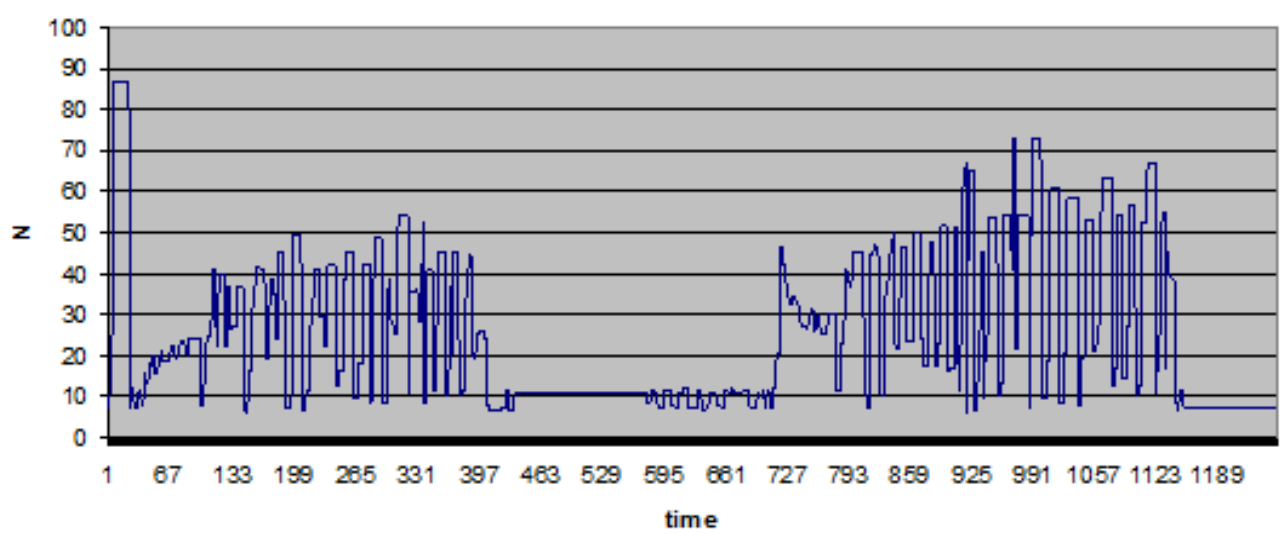

Fig. 6. Deviation of the thrust force in bi-cortical bovine bone drilling mode (full drill); drill bit diameter is $2.8 \mathrm{~mm}$; maximal speed is $2 \mathrm{~mm} / \mathrm{s}$; total time $-34.890 \mathrm{~s}$.

Time is scaled on the horizontal axis (x-axis) in conditional points $(\mathrm{CP})$, as in [20], but the numbers here are different according to the experiment. The sample time is $18 \mathrm{~ms}$; the real time interval is obtained multiplying CP interval by $100 \mathrm{~ms}$. From the graphics in Fig. 6, the following zones can be seen and they are commented as:

— searching the contact with the first (near) bone cortex: up to $30 \mathrm{CP}$;

- forming a center and resistant force identification, speed $0.5 \mathrm{~mm} / \mathrm{s}: 31-105 \mathrm{CP}$;

— first cortex drilling: up to $397 \mathrm{CP}$;

- decision for first cortex drilling end, speed reduction to $1 \mathrm{~mm} / \mathrm{s}$ and stop the motors: $398-403 \mathrm{CP}$;

— motion start again through marrow: from $580 \mathrm{CP}$;

— searching the contact with the far bone cortex: until $720 \mathrm{CP}$;

— forming a center and resistant force identification, speed $0.5 \mathrm{~mm} / \mathrm{s}: 721-795 \mathrm{CP}$;

— far cortex drilling: up to $1145 \mathrm{CP}$;

- decision far cortex drilling end, speed reduction to $1 \mathrm{~mm} / \mathrm{s}$ and stop the motors: 1146-1151 CP; 
— going back to reference position: after $1152 \mathrm{CP}$.

The total drilling time is about $35 \mathrm{~s}$. The drill bit penetration outside the far cortex is about $1 \mathrm{~mm}$, or less. The final result of the bicortical drilling is shown in Fig. 7, in which the drill bit is moved further to illustrate the penetration of the far cortex.

The speed reduction to $1 \mathrm{~mm} / \mathrm{s}$ at the drilling end allows forming the breakthrough very precisely, without bone debris. The surgeon is responsible for the orientation of the drill-bit, as well as he is responsible for the abutment of the hand-held robot on the bone.

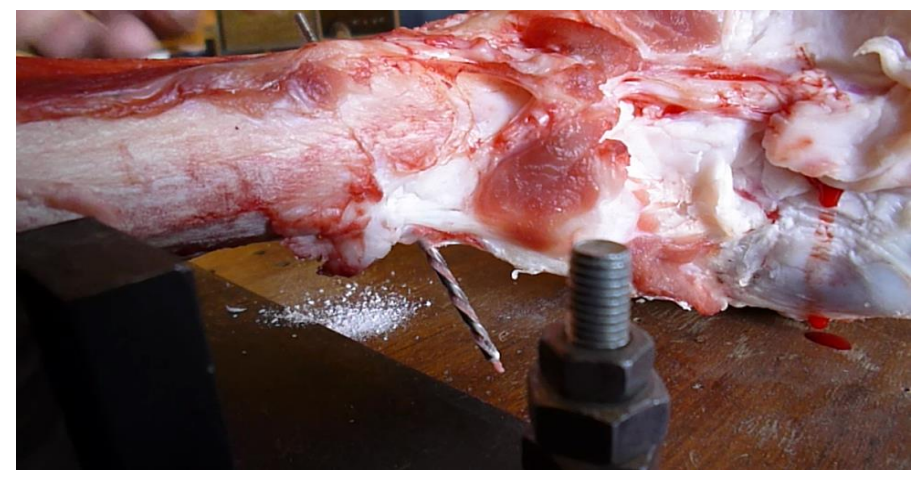

Fig. 7. The final snapshot of the experiment. The drill bit edge can be seen after additional force applying handily.

\section{DRILLING EXECUTION, MEASUREMENT AND DISPLAY INFORMATION}

The thrust force control during the drilling process is performed by translation motion control. It is realized by setting the concrete values of specific controller parameters, which define the maximal translation speed, maximal acceleration and target position in correspondence of the current position.

The drilling is executed very slowly, first $1 \mathrm{~mm}$ with $0.5 \mathrm{~mm} / \mathrm{s}$ speed, after the contact registration with the bone. This way, a 'center' is formed to eliminate the drill bit slide on the bone. That is important, because the drill bit is usually not perpendicular to the bone surface. The next $1 \mathrm{~mm}$ is drilling with $2 \mathrm{~mm} / \mathrm{s}$ and identification is performed for the concrete object under manipulation. The result is a value characterizing the bone density. Algorithm, for target position calculation, is created in dependence of arising resistant force. Its purpose is minimizing the difference between identified resistant force and the actual resistant force, measured by the force sensor.

The robot works only when the surgeon keeps the start button pressed. Any motion stops immediately, if the button is released. When the button is pressed again, 
the machine goes on program execution from the moment, when the motion has been stopped. The information seen on the display in real time shows what part of the task is executed up to the current moment. This way, the surgeon can control the drilling process in real time.

After the whole bone drilling, the following information can be seen on the display, if the measurements are integer numbers:

- first cortex thickness;

- distance between both cortexes (marrow cavity thickness);

- far cortex thickness;

- the whole depth measurement.

Figure 8 shows the measurements of the bone structure obtained in the experiment, presented in Fig. 5. In the case of real numbers (precision $0.1 \mathrm{~mm}$ ), the marrow cavity thickness isn't possible to be shown, but it is easy to be calculated.

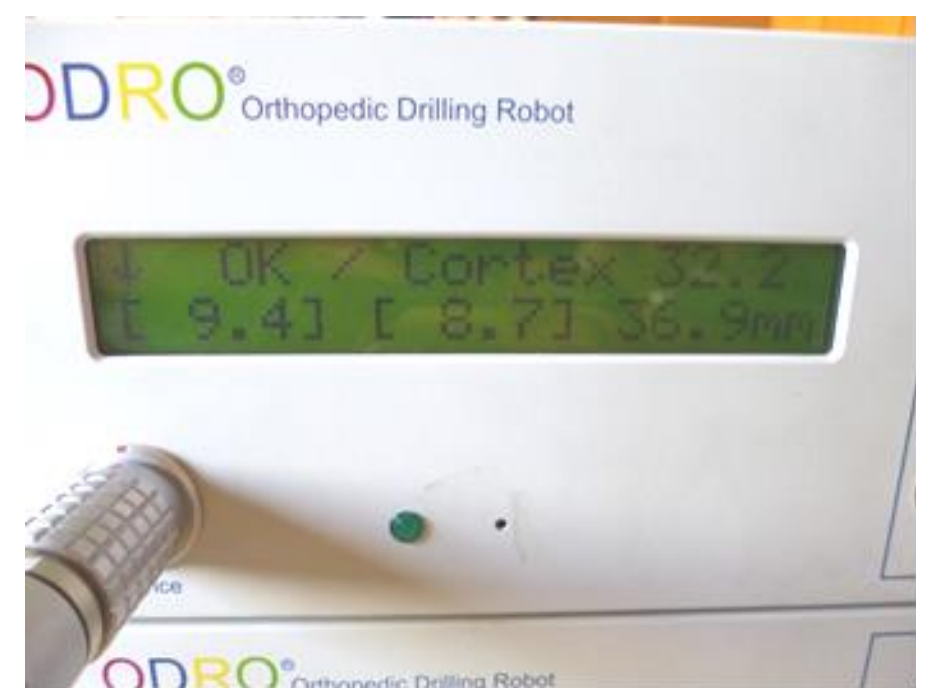

Fig. 8. Information after the whole drilling end: near cortex $-9.4 \mathrm{~mm}$; far cortex $-8.7 \mathrm{~mm}$; total - $36.9 \mathrm{~mm}$; marrow - $18.8 \mathrm{~mm}$ (after calculation).

In reality, the information shown in Fig. 8 has another very important meaning: elimination of a separate whole manipulation - measurement of already reached drilling hole depth. It is usually made after the drilling end and then it becomes clear, if the depth is right, or needs a correction. In our case, the value of the drilling 
hole appears online on the display. The measurement in the concrete case is performed with $0.1 \mathrm{~mm}$ accuracy. Moreover, the system capability is higher -4932 motor steps $/ \mathrm{mm}$. But, from practical view point (except the spine column operation [19]), the existing accuracy is enough, because the screw length possesses steps of $2 \mathrm{~mm}$. The information in Fig. 8 is also important, in the sense of optimal choosing the implant screw length.

\section{CONCLUSION}

The work presents new prototype of the medical bone drilling robot in the orthopaedic surgery - ODRO-2. The new mechanical structure design characterizes by parallel drives axes, instead of co-linear ones. It shortens the length of ODRO by one third, keeping in the same time all the functional characteristics. The last are verified by experiments which are comprised with the previous robot's (ODRO) behaviour.

Moreover, a new load cell is incorporated in the control block, which characteristics are better than the previous one. That reflects to less signal noise and better signal processing and better control, respectively.

Answering the surgeon's requirements for less robot weight, the later optimization is planned to make the corpse and other metal components by titanium alloy, which will reduce the weight by $40 \%$.

Concluding, the robot ODRO-2 is a more modern version having totally different concept, comprising with the previous one. It makes the automatic bone drilling machine more user-friendly, being in the same time a perfect assistant in orthopaedic surgery for solving various tasks in practice, which are difficult to be performed handily.

\section{REFERENCES}

[1] Hillery, M. T., I. ShuAib. Temperature Effects in the Drilling of Human and Bovine Bone. Journal of Materials Processing Technology, 92-93 (1999), 302-308.

[2] Clement, H., N. Heidari, W. Gechenig, A. M. Weinberg, W. Pichler. Drilling, not a Benign Procedure: Laboratory Simulation of True Drilling Depth, Injury. Int. J. Care Injured, $\mathbf{4 3}$ (1012), No. 6, 950-952, doi:10.1016/j.injury.2011.11.017; www.elsevier.com/locate/injury

[3] Lee, J. F. A New Thermal Model for Bone Drilling with Applications to Orthopaedic Surgery. Medical Engineering and Physics, 33 (2011), 1234-1244, doi:10.1016/j.medengphy.2011.05.014.

[4] Augustin, G., ET AL. Cortical Bone Drilling and Thermal Osteonecrosis. Clinical Biomechanics (Bristol, Avon), 27 (2012), 313-325.

[5] Sugano, N. Computer-assisted Orthopedic Surgery. Journal of Orthopaedic Sci- ence, 8 (2003), No. 24, 442-448. 
[6] Gomes, P. Surgical Robotics: Reviewing the Past, Analysing the Present, Imagining the Future. Robotics and Computer-Integrating Manufacturing, 27 (2011), 261-266.

[7] Beasley, R. A. Medical Robots: Current Systems and Research Directions. Journal of Robotics, Hindawi Publishing Corporation, 2012 (2012), Article ID40161, doi:10.1155/2012/401613.

[8] Rishi, A. M., R. P. NAYAK. Detection of Breakthrough during Bone drilling in Orthopaedic Surgery. International Journal for Technological Research in Engi- neering, 1 (2014), No. 9, ISSN (Online): 2347-4718, 794-798.

[9] Boindjiev, G., R. Kastelov, T. Boiadjiev, K. Delchev, K. Zagurski. Automatic Bone Drilling - More Precise, Reliable and Safe Manipulation in the Orthopaedic Surgery. Journal of Theoretical and Applied Mechanics, 46 (2016), No. 2, 51-64.

[10] Alam, K., A. V. Mitrofanov, V. V. Silberschmidt. Experimental Investigations of Forces and Torque in Conventional and Ultrasonically-assisted Drilling of Cortical Bone. Medical Engineering \& Physics, 33 (2011), 234-239.

[11] Boladjiev, G. BMM, Orthopaedic Device Useful Model, Certificate (Bulgarian Patent), No. 1053, Registry number: 1173, Priority: 2006, Year of publication 2008, 5 (in Bulgarian).

[12] Boiadjiev, G. BMM, Orthopedic Device Inventor's Certificate (Bulgarian Patent), No. 66136, Registry number: 109703, Priority: 2008, Year of publication 2011, 7 (in Bulgarian).

[13] Boiadjiev, G., T. Boiadjiev, V. Vitkov, K. Delchev, R. Kastelov, K. ZaGURSKI. Robotized System for Automation of the Drilling in the Orthopedic Surgery, Control Algorithms and Experimental Results, In Proceedings of the 9th IFAC Symp. on Robot Control SYROCO’09, Japan, Gifu, 2009, 633-638.

[14] Boiadjiev, T., K. Zagurski, G. Boiadjiev, K. Delchev, V. Vitkov, I. VeneVA, R. Kastelov. Identification of the Bone Structure during the Automatic Drilling in the Orthopedic Surgery. Journal LMBD Mechanics Based Design of Structures and Machines, 39 (2011), No. 2, 285-302, DOI:10.1080/15397734.2011.550863

[15] Boiadjev, G., R. Kastelov, T. Boiadjiev, V. Kotev, K. Delchev, K. ZaGURSKI, V. VITKOV. Design and Performance Study of an Orthopaedic Surgery Robotized Module for Automatic Bone Drilling. Journal of Medical Robots and Computer Assisted Surgery, 9 (2013), No. 4, 455-463, ISSN 1478-596X, Wileyonlinelibrary.com, DOI: $10.1002 /$ rcs.1479.

[16] Boiadjiev, T., K. Zagurski, G. Boiadjiev, K. Delchev, R. Kastelov. Automatic Bone Drilling in Orthopedic Surgery. Parameter Thing of an Active Force Control. Int. J. Applied Mechanics and Materials, 532 (2014), 208-211, Switzerland, Trans. Tech. Publications, ISSN 1660-9336, doi:10.4028/www.scientific.net/ AMM.532.208

[17] Boiadjiev, G., K. Delchev, T. Boiadjiev, K. Zagurski, R. Kastelov, V. VitKov. Controlled Trust Force Influence on Automatic Bone Drilling Parameters in the Orthopedic Surgery. Int. J. of Pure and Applied Math., 88 (2013), No. 4, 577-592.

[18] Boiadjiev, T., G. Boiadjiev, K. Delchev, R. Kastelov, K. Zagurski. Automatic Bone Drilling in Orthopedic Surgery. Overcoming of the Drill Bit Bending 
22 G. Boiadjiev, I. Chavdarov, K. Delchev, T. Boiadjiev, R. Kastelov, K. Zagurki

at the Second Cortex. Int. Journal Applied Mechanics and Materials, 664 (2014), 419-422, Switzerland, Trans. Tech. Publications, ISSN 1660-9336, doi:10.4028; http://www.scientific.net/AMM.644.419, http://www.ttp.net/978-3-03835-292-1.html

[19] Boiadjiev, T., G. Boiadjiev, K. Delchev, R. Kastelov, K. Zagurski. Eliminating of Far Pedicle Cortex Perforation by Automatic Spine Drilling. Int. Journal of Applied Mechanics and Materials, 799-800 (2015), 505-508, Switzerland, Tech. Publications, doi: 10.4028 www.scientific.net/AMM.799-800.505. ISSN 1660-9336.

[20] Boiadjiev, T., G. Boiadjiev, K. Delchev, K. Zagurski, R. Kastelov. Far Cortex Automatic Detection aimed for Partial or Full Bone Drilling by a Robot System in Orthopaedic Surgery. J. Biotechnology \& Biotechnological Equipment, 2016, Taylor\&Francis, ISSN: 1310-2818 (Print) 13143530 (Online) Journal homepage: http://www.tandfonline.com/loi/tbeq20, http://dx.doi.org/10.1080/13102818.2016.1234947 